\title{
Application of various forms of information and communication technologies in the context of distance learning
}

\author{
A.V. Platonova ${ }^{1 *}$, E.Ya. Yartseva ${ }^{2}$, and L.E. Shvedova ${ }^{3}$ \\ ${ }^{1}$ V.I. Vernadsky Crimean Federal University, Simferopol, Russia \\ ${ }^{2}$ V.I. Vernadsky Crimean Federal University, Simferopol, Russia \\ ${ }^{3}$ V.I. Vernadsky Crimean Federal University, Simferopol, Russia
}

\begin{abstract}
The article shows the possibility of using information technology in the context of distance learning. The teaching process is always based on the transferring of information from teacher to student. As to distance education, the most important are the following: educational information; educational technologies; information technology. When choosing methods for usage in distance learning, it is important to take into account that certain methods are best suited to the characteristics of the trainees, the specifics of particular subject areas and the general types of educational tasks and exercises. Distance learning network technologies are especially important when organizing joint educational programs, since they allow the most complete implementation of the principles of the distribution of educational and human resources. The article reveals the forms of information and communication technologies used in modern higher educational institutions in the field of digital education. The mandate for the usage of ICT in education is being clarified. Various educational tools using ICT have several aspects, including: stimuli, information, education and methods. The empirical research was carried out on the basis of the analysis of social networks in the context of distance learning.
\end{abstract}

\section{A problem statement}

The urgency of the research topic is due to the fact that the process of change of the modern education system is associated with the introduction of new educational technologies. Along with the traditional education systems, a new form is also successfully developing distance learning. Distance learning uses extensively such educational technologies as the Internet and information and communication technologies, at the same time preserving educational technologies, methods, forms and means of traditional education. Equipping the education system with information and communication technologies is one of the tasks of modernizing of the Russian education system.

${ }^{*}$ Corresponding author: prof-ped.gpa@mail.ru 
The education system is integrating into the online world to meet the growing needs of the country's economic development. The process of creating a common economic space for European countries enhances the process of globalization and modernization of the Russian educational system. The Bologna Process proves this fact, since its development in the field of Russian education has acquired a certain importance at all stages of education in accordance with the cognitive needs of students, interests and abilities, the variability of the content of education, organizational forms and methods. Therefore, in order to achieve the quality of education, it is necessary to introduce new forms of education in primary, secondary and higher education. In this regard, distance learning and its technologies are of particular relevance [1].

It is also worth noting that the period of development of modern society is characterized by a strong influence of computer technologies that permeate all spheres of human activity and ensure the spread of information flows in society, and an important component of the formation of all these processes is the computerization of education.

During the past decade, the widespread use of computer technologies in education has led to an increasing interest in teaching sciences. A great contribution to solving the problems of educational computer technologies was made by Russian and foreign scientists: G.R. Gromov, V.Ya. Gritsenko, V.F. Sholokhovich, O.Ya. Agapova, O. Odin, S. Papert, G. Kleiman, B. Sendov, B. Hunter and others.

Information and communication technologies (ICT) are general concepts that describe various devices, mechanisms, methods and algorithms for information processing. The most important modern information and communication technological equipment are computers equipped with appropriate software and telecommunication facilities, as well as information arranged on these devices.

The process of informatization of modern society is closely related to the process of informatization of all forms of educational activity, which is characterized by the improvement of modern information and communication technologies (ICT) and the process of their large-scale expansion. In modern systems of open and distance education, these technologies are actively used to transfer information and ensure interaction between teachers and students. Modern educators should not only possess knowledge in the field of ICT, but also become experts in their application in professional activities.

The word "technology" has Greek roots and in translation means science, a set of methods and techniques for refinement or manufacturing raw materials, stuff, semi-finished products, articles and converting them into consumer goods. The modern understanding of this word includes the application of scientific and engineering knowledge to solve practical problems [2]. In this case, information and telecommunication technologies can be considered as technologies that are designed to process and transform information. With the emergence of such an integral part of the educational process as informatization, it becomes desirable to modify its taskы. The main things are:

- improving the quality of training of specialists through the use of modern information technologies in the educational process;

- using active teaching methods and thereby increasing the creative and intellectual component of educational activities;

- integration of various types of educational activities;

- adaptation of training in information technology to the individual characteristics of a student;

- ensuring the continuity of education and upbringing;

- development of information technologies for distance learning;

- software and methodological support for improving the educational process [3].

The ICT form can be classified according to many parameters:

1. For solving educational problems: 
- means of providing basic training (electronic textbooks, training systems, knowledge control systems);

- practical training tools (questionnaires, seminars, virtual constructors, simulation programs, simulators);

- aids (encyclopedias, dictionaries, anthologies, educational computer games, multimedia training courses);

- complex device (console).

2. Through the function of the organization in the educational process:

- information and training (electronic libraries, electronic books, electronic journals, dictionaries, reference books, training computer programs, information systems);

- interaction (email, electronic conferencing);

- search (catalog, search engine).

3. By the type of information:

- electronic and information resources containing textual information (textbooks, problem books, tests, dictionaries, reference books, encyclopedias, magazines, digital data, software and educational materials);

- electronic and information resources with visual information (collection: photographs, portraits, illustrations, video clips of processes and phenomena, experimental presentations, video tours; statistical and dynamic models, interactive models; symbolic objects: diagrams, etc.);

- electronic and information resources with audio information (recordings of poetry, educational materials, musical works, biological and inanimate natural sounds, synchronized audio objects);

- electronic and information resources with audio and video information (audio and video objects with living and nonliving properties, thematic excursions) [4].

\subsection{The objective of the work}

Social networks are one of the forms of information and communication technologies. Many schools, universities, teachers have pages on social networks. Academic groups organize online communities, and teachers create separate work pages to communicate and exchange information with students. The potential and features of the usage of social networks are mainly due to their availability and speed of information transferring, and their use for educational purposes allows classes to be conducted outside the classroom, which additionally motivates students.

To determine popular and accessible social networks among students of the Federal State Autonomous Educational Institution of Higher Education "V.I. Vernadsky Crimean Federal University" of the experimental group, a survey was conducted on the Internet portal Google Forms.

The survey includes 10 questions and suggested answers:

1. Are you logged on a virtual social network?

2. What social network do you have a profile page on?

3. From what device do you most often view pages on social networks?

4. Are you a member of the educational social media community?

5. In your opinion, does the educational community contribute to your academic success?

6. Do you want to use social media in class?

7. In your opinion, which social network is the most convenient for learning?

8. Under what circumstances do you think it would be more effective to use social media in class?

9. Are you ready to broadcast live on social media? 
10. Do you want to take a virtual course on social media?

After a statistical study of students, it turned out that the most accessible social networks are VKontakte and Instagram. Of the 92 students surveyed, each of them used these social networks for personal communication, as well as for the exchange of information related to the educational process.

The purpose of using the social network VKontakte is in this case the ability to view educational videos, which are usually not available for viewing in the classroom, since the entire academic group of some university students with interest accepts and approves the integration of social networks into their educational process, as well as the possibility of using them.

The social network VKontakte, one of the new generation Internet services Web2.0, is a system that allows users to send text messages (up to 700 characters), create communities (groups, official pages and meetings), publish records, videos, photos). Users have the right to create independently, use and determine the content of their personal pages and the conditions under which other users can use them.

Communication in VKontakte is a kind of chat, to become a member of which you can only by invitation of users. In a conversation, you can chat with several users at the same time. Communication takes place in real time: all messages sent by the user to the conversation will be visible to all its participants. You can give the conversation a title or create a cover. You can attach audio and video files, photos, documents, voice messages, polls and indicate your location for conversations with participants. In other words, students have the opportunity to exchange photos of teaching materials, post class schedules, and the leader of the group can find out beforehand who will be absent from the class, etc.

However, one should take into account the role of a teacher as a direct participant and moderator of such conversations. The social network Instagram ranks second among students. This service was originally used for instant photo sharing. The Instagram application, developed back in 2010, is one of the most popular among modern student youth: almost every student checks this social network every day and looks at the stories and publications of the people they follow. This fact inspires the use of this application for educational purposes, namely to improve the professional and language skills of radio engineering students.

For the organization of distance e-learning, it is recommended to create a separate account to which all students of the academic group subscribe. Subscribers can regularly follow updates and participate in various forms of work provided by the educator. It is important for educators to follow the algorithm of action when using the social network Instagram, so that the guided self-study and distance learning were not spontaneous and so that students knew the schedule for publishing or going online beforehand.

In the course of this research, students noted that the most convenient way to complete assignments is to use mobile devices. The implementation of such a vocabulary test within the VKontakte dialogue frame takes very little time. Students skip the stage of adaptation to a new learning environment, which allows creating the informal communication between teachers and students and in an organized way helps students to point to the fact that they can complete such an assignment on the Internet, for example, while they are on their way home or just during leisure time.

Besides, students are required to conduct such surveys before writing control tests after passing a certain unit of the textbook. Analyzing the results of the pedagogical experiment, we can say that the seemingly aimless pastime in social networks is transformed into something useful, contributing to the most effective assimilation of educational material. The educational-methodical complex Face2Face Elementary is used by a group of students to supply them with watching of video materials. The methodical work with the video material of the Face2Face educational complex is organized by teachers in three stages: 
preparation, text or presentation, i.e. direct usage of video material, as well as post-text or post-presentation.

As a result of the exercise, the teachers noted that there is a positive reaction of students to the introduction of the social network Vkontakte into the course of study. Students enjoy completing multiple-answer assignments, watching instructional videos in a relaxed environment, and listening to instructional audio as homework.

\section{Results of the research}

In modern conditions, for the effective work of higher educational institutions, it is necessary to use technologies that allow to use information faster and more effectively, to plan the work of the structural sector of education and of separate teachers, to maintain communication and expand the opportunities for educational and scientific activities. Various Internet services corresponds to this task adequately, allowing you to create a unified educational information environment, to form an open and accessible platform for high-quality educational resources, and create a new culture of thinking for teachers and students, which is so necessary in modern society.

Interest arising from the needs of the individual, motivation as a source of activity, as well as internal stimuli and emotional systems are the key factors of learning at a university. In the field of modern education, the following information technologies are most widely used: verified electronic textbooks, interactive learning resources (machines), virtual environment (virtual reality, classrooms, museums, etc.), interactive learning resources (machines), reduced electronic databases, reduced reference and information sources (online translations, electronic dictionaries, encyclopedias, etc.), electronic library, digital collection (photographs, sound and video files).

All of the above mentioned technologies can be included to and published on social networks, thereby reducing the time it takes to find the information you need. Therefore, the social network VKontakte has great opportunities - it is enough to create a community or a dialogue with invited users, in a word, a platform in which there is an electronic library with textbooks and reference materials, a media library and other information.

A modern social network is rapidly developing social software that allows you to receive easily a variety of information and to communicate with other users. The widespread use of social networks, as well as the distribution of mobile devices, has led to the fact that social networks inevitably become an integral part of the educational environment of higher education institutions.

Today social media is a new learning environment where students mainly read or view educational content, share comments or audio and video materials that they have made themselves owing to what they have learned earlier in class. One cannot ignore the current tendency that today's educational process takes place not only within the walls of the university, but can also take place simultaneously, for example, in the Instagram or VKontakte social network feed.

The positive things when using social networks in learning are: posting educational content, improving communication and interaction, promoting collaboration and group work, providing and receiving feedback in a synchronized manner. On the other hand, social media also has its drawbacks: too much entertainment information, lack of strict control, disregard for ethical issues, and inaccurate content. In general, the use of social media in an educational context remains controversial and all the positive and negative moments should be considered to make it more effective for both educators and students.

The use of non-professional social networks to organize vocational training provides many psychological advantages for teachers and students over traditional methods of interaction. 
1. Owing to the information posted on the user profile page containing user credentials and other information related to the course, in the social media environment teachers introduce students to each other faster. Usually a profile contains the user's name or network alias, place of residence, circle of interests, audio and video recordings of the user, a list of friends, groups and communities to which the user joins, information on the "wall", and so on. All this allows you to make acquaintances, communicate, create groups, etc. In addition, on the VKontakte social network, participants usually have connections not only within the framework of the training course, but also with a wider range of users. Thanks to this, each course participant can expand and enrich their communication significantly.

2. Social media helps to break down hierarchical boundaries between users. Often, for various reasons, including cultural ones, there is no communication between the organizer and the students of the course: some students do not consider it possible to contact the teacher or the head of the course, first of all, regarding problems that arise. This can affect their academic progress and the general impression of the course.

Social media can remove this barrier and facilitate greatly the direct communication between different levels of the hierarchy. For teachers, for instance, academic group leaders, it is a convenient way to get feedback and to take measures to eliminate any learning difficulties in proper time. The problems associated with the low level of net etiquette of many users are easier to prevent by developing and accepting the rules of behavior on the network, which are contained in the algorithm of actions, a special instruction that teachers work out during university studies.

The cohesion of the research group is a beneficial effect of using social networks in the educational process. At the beginning of the training, course participants may not know the teacher, feel a little alienated and "lost". Social networks, due to their democratic, uncritical and open nature, allow you to establish informal communication between teachers and students as quickly as possible and help to organize an educational process focused on the student's personality. The participants of the training (under the guidance of the teacher) begin to feel "their own" soon: they find topics for communication, show a high tolerance for mistakes and difficulties of their "fellow students", readiness to help each other, and are interested in the course or the audience. The community serves as a "support group" that helps to overcome self-doubt, motivates not to quit studying during the first year.

3 . The speed of adaptation to the new communicative space is another useful result of transferring some trainings to non-professional social networks. Interaction in a social environment helps to increase motivation to learning. The existing rating system in social networks (users and the content they create, that is, the content of the site) can be used as a tool to reward the efforts of participants in addition to the indicators of their progress. The points earned can be used not only for academic success, but also for help, support, active participation and timely completion of assignments.

Awards can be given not only to students, but also to teachers. All of this helps to maintain participants' interest in the work of the training course as long as ethical standards are maintained and the other party is respected.

Analyzing the theoretical framework dedicated to our research, as well as regulatory documents, we came to the conclusion that students should have a whole range of knowledge, and teaching involves the development of students' versatile abilities. Since students are involved in the process of such training, which uses innovative methods, ICT technologies, it is necessary to talk about the formation of information and communication skills in students. 


\section{Conclusions}

We determined that the formation of information and communication skills in students means the use of information and communication technologies, including social networks, independent replenishment of the vocabulary of the professional field, etc.

The integration of social networks into the educational process of students brings positive results: firstly, students respond positively to assignments, enjoy the learning process, do not make mistakes when performing lexical and grammatical exercises in controlled tests developed on social networks, and also provide teachers with their own ideas for working with social networks. At the same time, it should be recognized that the results are not positive and that the integration of social networks into learning will not be effective if the step-by-step algorithms developed for learning using social networks are not determined.

\section{References}

1. I.N. Babich, New Educational Technologies in the Information Age, Foundation for New Technologies in Education "Baytik", 68-70 (2019)

2. V.A. Slastenin, B.C. Podymova, The Teacher's Readiness for Innovation, Pedagogical Science and Education, 1, 32-37 (2016)

3. Yu.G. Molokov, A.V. Molokova, Topical Issues of Informatization of Education (2016)

4. I.M. Ibragimov, Information Technologies and Distance Learning Tools, 336 (2017)

5. A.G. Abramov, M.V. Bulgakov, A.D. Ivannikov, A.V. Sigalov, Federal Portal "Information and Communication Technologies in Education": Five Years in Educational Runet, Journal "Distance Virtual Learning", 3, 14-30 (2019)

6. N.N. Dvulichanskaya, Interactive Teaching Methods as a Means of Forming Key Competencies, Science and Education: Electronic Scientific and Technical Edition, 4 (2018)

7. A.A. Kuznetsov, E.K. Henner, W.R. Imakaev etc, Information and Communication Competence of a Modern Teacher, Informatics and Education, 4 (2018)

8. A.O. Maltsev, Communication Means of Distance Learning, Basic Research, 3, 106 (2019)

9. S.A. Pavlova, R.Ya. Trofimova, Information and Technical Teaching Aids in Primary School, Primary school, 5 (2016)

10. D.M. Boyd, Social Network Sites: Definition, History, and Scolarship, Journal of Computer-Mediated Communication, 13(1), 210-230 (2017)

11. Working the Twittersphere: Microblogging as Professional Identity Construction, A Networked Self: Identity, Community, and Culture on Social Network Sites, 11, 232250 (2018) 